\section{What do markers of bone formation tell us in equine nutritional studies?}

\author{
Brian D. Nielsen \\ Department of Animal Science, Michigan State University, East Lansing, MI
}

\section{Introduction}

Skeletal injuries in performance horses are quite common. Research investigating ways to decrease injuries has been limited due to difficulty in non-invasively measuring the response of bone to a given treatment. With the use of biochemical markers of bone turnover, more projects are being conducted and advancements in improving bone health are occurring. However, such assays are expensive and researchers often need to make decisions as to when their use is justified. By reviewing the responses of bone markers in nutritional studies and comparing them to responses in exercise studies, the objective is to determine whether bone is more likely to respond to a dietary or exercise treatment.

\section{Materials and methods}

The results of studies using the marker of bone formation osteocalcin (OC), as well as markers of bone resorption pyridinoline and deoxypyridinoline crosslinks (DPD) and carboxy-terminal pyridinoline cross-linked telopeptides of type I collagen (ICTP), were compiled and summarized.

\section{Results}

Of seven nutritional studies using $\mathrm{OC}$ concentrations to examine dietary impacts on bone, five showed no differences while two reported a trend for differences (Table 1). Of three

Table 1 Studies evaluating markers of bone metabolism in response to alterations in nutrition or exercise.

\begin{tabular}{|c|c|c|c|c|c|}
\hline Nutritional Study & $\begin{array}{l}\text { Parameter } \\
\text { altered }\end{array}$ & OC & DPD & ICTP & $\begin{array}{c}\text { Bone } \\
\text { Quality }\end{array}$ \\
\hline Nielsen 1998 & $\mathrm{Ca}, \mathrm{P}$ & No & & & $\mathrm{T}$ \\
\hline Fenton 1999 & Glucosamine & No & & & \\
\hline Lang 2001a & Supplemental Si & $\mathrm{T}$ & $\mathrm{T}$ & No & \\
\hline Lang 2001 b & Supplemental Si & No & No & Yes & \\
\hline Nielsen 2002 & Anabolic supplement & No & & No & No \\
\hline Woodward 2005 & Omega 3 fatty acids & No & & No & \\
\hline Turner 2005* & Supplemental Si & $\mathrm{T}$ & Yes & & $T$ \\
\hline Exercise Study & \begin{tabular}{|l}
$\begin{array}{l}\text { Parameter } \\
\text { altered }\end{array}$ \\
\end{tabular} & OC & DPD & ICTP & $\begin{array}{c}\text { Bone } \\
\text { Quality }\end{array}$ \\
\hline Nielsen 1998a & Onset of training & Yes & & & Yes \\
\hline Nielsen 1998b & Onset of training & Yes & & & Yes \\
\hline Fenton 1999 & Longeing & No & & & \\
\hline Hoekstra 1999 & Stalling/pastured & Yes & Yes & & Yes \\
\hline Bell 2001 & Stalling/pastured & Yes & & No & Yes \\
\hline Nielsen 2002 & Weight carrying & Yes & & Yes & Yes \\
\hline Hiney 2004a* & Stalling/forced exercise & Yes & No & & Yes \\
\hline Hiney $2002,2004 b$ & Stalling/forced exercise & $\mathrm{T}$ & Yes & & Yes \\
\hline
\end{tabular}

nutritional studies that evaluated DPD concentrations, one showed a treatment difference, one showed a trend for a difference, and one showed no difference. Of four nutritional studies that evaluated ICTP concentrations, only one showed a treatment difference. Only three of the nutritional studies made an evaluation of bone quality (either mineral content or breaking strength). One reported no difference while two showed trends for differences in at least one measured parameter of bone quality.

In contrast, in eight studies examining the impact of exercise on $\mathrm{OC}$, six showed differences, one showed a trend for a difference and one reported no difference. Three studies evaluated DPD in response to alterations in exercise and two studies reported differences while one did not. Two studies used ICTP and one showed a treatment difference while the other did not. Seven of the studies evaluated bone quality and all seven reported a difference in at least one measured parameter.

\section{Discussion}

This post-hoc analysis suggest dietary treatments usually failed to result in differences in markers of bone metabolism. In five out of seven nutritional studies, no differences $(P<0.05)$ were seen in any biochemical markers. Additionally, no differences $(P<0.05)$ in measurements of bone quality were seen in the three studies that evaluated such, though modest trends for treatment differences were seen in two of them. In contrast, variations in exercise resulted in differences in bone marker concentrations and in bone quality in seven of eight studies.

A review of papers presented at the 2001 and 2003 Equine Nutrition and Physiology Symposiums using markers of bone formation reveals similar findings. Three of five studies failed to find alterations in either bone metabolism markers or bone quality in response to alterations in diet. The studies evaluated increased concentrations of trace minerals (Kavazis et al. 2001), supplemental manganese (Sobota et al. 2001), and inorganic mineral supplementation (Baker et al. 2003). Concentrations of ICTP, but not $O C$, were altered in response to feeding high Ca, P and Mg (Michael et al. 2001). Peterson et al. (2001) found OC was altered when young horses were fed a diet formulated for rapid growth as compared to slow growth. Unfortunately, no measurements of bone quality were reported in either of the latter two studies.

The two studies that examined the response of horses to alterations in exercise reported that both bone metabolism markers and bone quality were altered. These studies examined forced exercise before the onset of initial training (Williams et al. 2003) and disuse associated with stalling (Henry et al 2003).

\section{Conclusions}

These results suggest exercise plays a much greater role in bone metabolism than do differences in nutrition, particularly if the nutritional differences are relatively minor. This suggests that the horse is capable of altering its absorption of 
nutrients to maintain bone health to a much greater degree than it is of maintaining bone strength if not provided adequate exercise.

\section{References}

Baker L. A., Kearney-Moss T., Pipkin J. L., Bachman R. C., Haliburton J. T. and Veneklasen G. O. (2005): The effect of supplemental inorganic and organic sources of copper and zinc on bone metabolism in exercised yearling geldings. Proc 18th Equine Nutrition and Physiology Society; 2003 June 4-7; Lansing, MI, USA, 100105.

Bell R. A., Nielsen B. D., Waite K., Rosenstein D. and Orth M. (2001): Daily access to pasture turnout prevents loss of mineral in the third metacarpus of Arabian weanlings. J Anim Sci 79, 1142-1 150

Fenton J. I., Orth M. W., Chlebek-Brown K. A., Nielsen B. D., Corn C. D., Waite K. L. and Caron J. P. (1999): Effect of longeing and glucosamine supplementation on serum markers of bone and joint metabolism in yearling Quarter Horses. Can J Vet Res 63, 288291

Henry J. C., Cooper S. R., Freeman D. W. and Kropp J. R. (2005): Effects of exercise on bone metabolism in yearling horses. 2003. Proc 18th Equine Nutrition and Physiology Society; 2003 June 47; Lansing, MI, USA, 230-235

Hiney K. M. (2002): The effecs of short term high intensity exercise on bone parameters of immature animals. Ph.D. Dissertation. Michigan State University. 2002.

Hiney K. M., Nielsen B. D. und Rosenstein D. S. (2004b): Short-duration exercise and confinement alters bone mineral content and shape in weanling horses. J Anim Sci 82, 2313-2320

Hiney K. M., Nielsen B. D., Rosenstein D. S., Orth M. W. and Marks B. P. (2004a): High-intensity exercise of short duration alters bovine bone density and shape. J Anim Sci 82, 1612-1620

Hoekstra K. E., Nielsen B. D., Orth M. W., Rosenstein D. S., Schott H. C. and Shelle J. E. (1999): Comparison of bone mineral content and bone metabolism in stall- versus pasture-reared horses. Equine Vet J Suppl 30, 601-604

Kavazis A. N., Ott E. A., Johnson E., McDowell L., Sobota J. S. and Kivipelto J. (2005): Influence of trace mineral intake of mares on the trace mineral status of their foals. Proc 17th Equine Nutrition and Physiology Society; 2001 May 31 -Jun 2; Lexington, KY, USA, $24-25$

Lang K. J., Nielsen B. D., Waite K. L., Hill G. M. and Orth M. W. (2001a): Supplemental silicon increases plasma and milk silicon concentrations in horses. J Anim Sci 79, 2627-2633

Lang K. J., Nielsen B. D., Waite K. L., Link J., Hill G. M. and Orth M. W. (2001 a): Increased plasma silicon concentrations and altered bone resorption in response to sodium zeolite A supplementation in yearling horses. J Equine Vet Sci 21, 550-555
Michael E. M., Potter G. D., Mathiason-Kochan K. J., Gibbs P. G., Morris E. L., Greene L. W. and Topliff D. (2005): Biochemical markers of bone modeling and remodeling in juvenile racehorses fed differing levels of minerals. Proc 17th Equine Nutrition and Physiology Society; 2001 May 31 -Jun 2; Lexington, KY, USA, 117-121

Nielsen B. D., O'Connor C. I., Rosenstein D. S., Schott H. C. and Clayton H. M. (2002): Influence of trotting and supplemental weight on metacarpal bone development. Equine Vet J Suppl 34, 236-240

Nielsen B. D., Potter G. D., Greene L. W., Morris E. L, Murray-Gerzik M., Smith W. B. and Martin M. T. (1998a): Characterization of changes related to mineral balance and bone metabolism in the young racing Quarter Horse. J Equine Vet Sci 18, 190-200

Nielsen B. D., Potter G. D., Greene L. W., Morris E. L., Murray-Gerzik M., Smith W. B. and Martin M. T. (1998b): Response of young horses in training to varying concentrations of dietary calcium and phosphorus. J Equine Vet Sci 18, 397-404

Peterson E. D., Siciliano P. D., Turner A. S., Kawcak C. E. and Mcllwraith C. W. (2005): Effect of growth rate on serum-bone-specific alkaline phosphatase and osteocalcin in weanling horses. Proc 17th Equine Nutrition and Physiology Society; 2001 May 31 -Jun 2; Lexington, KY, USA, 186-187

Sobota J. S., Ott E. A., Johnson E., McDowell L., Kavazis A. N. and Kivipelto J. (2005): Influence of manganese on yearling horses. Proc 17th Equine Nutrition and Physiology Society; 2001 May 31 Jun 2; Lexington, KY, USA, 136-137

Turner K. K., Nielsen B. D., O'Connor C. I., Rosenstein D. S., Marks B. P and Orth M. W. (2005): Bone characteristics and turnover after silicon supplementation. Proc. 19th Equine Science Society; 2005 Jun 1-3; Tucson, AZ, USA 31-36

Williams J. L., Potter G. D., Michael E. M., Gibbs P. G., Scott B. D., Hood D. M. and Morris E. L. (2005): Pretraining influence on bone growth and development in weanling horses. Proc 18th Equine Nutrition and Physiology Society; 2003 June 4-7; Lansing, MI, USA, 32-37

\section{B. D. Nielsen}

Department of Animal Science

Michigan State University,

East Lansing, Ml 48824

USA

bdn@msu.edu 